\title{
Superstorm Sandy's impact on the provision of WIC (Special Supplemental Nutrition Program for Women, Infants, and Children) services in New York State
}

\author{
Michelle Wemette ${ }^{1,2, *}$, Asante Shipp Hilts ${ }^{1,2}$, Stephanie R Mack ${ }^{1}$, Yunshu Li ${ }^{1}$, \\ Millicent Eidson ${ }^{1,2}$, Loretta A Santilli ${ }^{3}$, Trang Nguyen ${ }^{1,2}$ and Guthrie S Birkhead ${ }^{2,4}$ \\ 'Office of Public Health Practice, New York State Department of Health, 1006 Corning Tower, ESP, Albany, NY \\ 12237, USA: ${ }^{2}$ Department of Epidemiology and Biostatistics, University at Albany School of Public Health, \\ Rensselaer, NY, USA: ${ }^{3}$ Division of Nutrition, New York State Department of Health, Albany, NY, USA: ${ }^{4}$ Office of \\ Public Health, New York State Department of Health, Albany, NY, USA
}

Submitted 11 June 2017: Final revision received 18 0ctober 2017: Accepted 21 November 2017: First published online 10 January 2018

\begin{abstract}
Objective: Services provided by the Special Supplemental Nutrition Program for Women, Infants, and Children (WIC) were interrupted in 2012 when Superstorm Sandy struck New York State (NYS). The present study evaluates the impact on WIC providers.

Design: A focus group, telephone interviews and anonymous online survey were conducted. Qualitative data were analysed by coding transcribed text into key words and identifying major and minor themes for strengths, challenges and recommendations using national public health preparedness capabilities. Survey responses were analysed quantitatively; reported challenges were classified by preparedness capability.

Setting: The focus group was held at a 2014 regional WIC meeting. Interviews and a survey were conducted via telephone in 2014 and online in 2015, respectively. Subjects: WIC staff representing New York City and three NYS counties.

Results: In the focus group ( $n$ 12) and interviews ( $n$ 6), 'emergency operations coordination' was the most cited capability as a strength, 'environmental health protection' (against environmental hazards) as a challenge and 'flexibility' (on rules and procedures) as a recommendation. In the survey ( $n 24)$, the capability 'information sharing' was most often cited as a challenge. Most staff (66.6\%) reported their programmes were at least somewhat prepared for future weatherrelated disasters. Only $16.7 \%$ indicated having practiced a work-related emergency response plan since Sandy. Staff who practiced an emergency response plan were more likely to indicate they were prepared $(P<0.05)$.

Conclusions: The study identified WIC programme areas requiring preparedness improvements. The research methodology can be utilized to assess the continuity of other public health services during disasters.
\end{abstract}

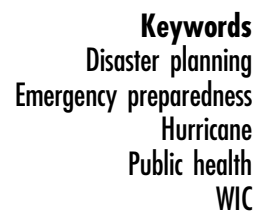

The Special Supplemental Nutrition Program for Women, Infants, and Children (WIC) provides supplemental food, nutrition education/counselling and linkages with health and social services for low-income, at-risk populations in New York State (NYS). These services are provided by WIC agencies with sites located in local health departments (LHD), hospitals and other community-based organizations. On 29 October 2012, Superstorm Sandy (Sandy) struck NYS, directly causing forty-eight deaths ${ }^{(1)}$. The most complete damage estimates are for New York City (NYC), which reported \$US 4.5 billion in damages to city agencies (out of an estimated \$US 19 billion in total damages to NYC). Sandy also interrupted the operation of health-care facilities ${ }^{(2)}$ and the delivery of routine public health services ${ }^{(3,4)}$.

WIC providers offer vital services to vulnerable populations with unique health needs. The Centers for Disease Control and Prevention (CDC) acknowledges the distinct health issues faced by pregnant women and infants during and following disaster events ${ }^{(5)}$. It recommends that disaster preparedness planning and response efforts account for the effects that disrupted public health systems may have on pregnant women, postpartum/breast-feeding women and their infants. In addition, CDC's Division of 
Reproductive Health has guided the development of a set of post-disaster epidemiological indicators for pregnant and postpartum women and their infants intended to evaluate the impact of disasters on and the needs of these populations following disasters ${ }^{(6)}$. Access to WIC services was included as an indicator.

Efforts to incorporate the health needs of pregnant and postpartum women and infants into disaster preparedness and response plans are justified by a growing body of evidence highlighting the adverse effects that disasters can have on the health of this vulnerable group. Women characterized as having 'high hurricane' exposure, a classification indicative of experiences such as severe damage to one's home or being without electricity for greater than one week among others, have been found to be at an increased risk of giving birth to infants with low birth weight ${ }^{(7)}$. Women with this exposure were also found to be at increased risk for post-traumatic stress disorder and depression ${ }^{(8)}$.

Despite the importance of WIC services, the impact of weather-related disasters like Sandy on WIC services or WIC programmes' preparedness for and response to such emergency events is not well studied. However, the impact of Sandy on routine public health services such as tuberculosis control programmes ${ }^{(3)}$ and services for injection drug users $^{(4)}$ has been previously described. We have previously studied the impact of Sandy on various parts of the public health system in New York ${ }^{(9-11)}$. This research was funded in 2013 by the CDC to identify ways to improve preparation, response and recovery efforts for future disasters. The aim of the present study was to collect and analyse WIC-specific information as part of the overall NYS evaluation.

\section{Methods}

The geographic area for the present study was focused on the areas of NYS most heavily impacted by Sandy, including Nassau County, Suffolk County, Westchester County and NYC. To support the study, a Sandy Guidance Team was established to offer study oversight. The Guidance Team represented multiple agencies, including WIC providers from declared disaster areas in NYS, NYS Department of Health (NYSDOH) staff, LHD staff, academic partners including faculty with qualitative and quantitative research expertise, and emergency managers.

A mixed-methods (both qualitative and quantitative) approach was utilized to evaluate the impact of Sandy on WIC providers. Feedback was collected from WIC staff in the three counties and NYC during three phases: a focus group, semi-structured interviews and an anonymous survey. Members of the Guidance Team provided guidance for all three phases. Approval from the NYSDOH Institutional Review Board was obtained for all protocols and questionnaires utilized in conducting this research. For the present study purposes, the Sandy preparedness, response and recovery period was defined as 26 October 2012 to 21 November 2012.
The focus group served as an initial step in pinpointing strengths, challenges and recommendations related to eleven Public Health Preparedness Capabilities developed by the $\mathrm{CDC}^{(12)}$. Focus group participants were recruited from representatives of WIC programmes (affected by Sandy) attending the annual NYSDOH Metropolitan Area Regional Office WIC Directors' Meeting held in June 2014 in NYC. Meeting attendees were instructed that they must represent a WIC programme that served an area impacted by Sandy to be eligible to participate in the focus group. All attendees who met this requirement were invited to participate. Participants included WIC programme directors, coordinators and other staff, and one vendor management agency (VMA) which works with grocery stores and pharmacies where WIC cheques are redeemed. The focus group was intended to collect WIC provider feedback regarding the strengths and challenges of their Sandy response and recovery activities and recommendations for future preparedness. A pre-developed list of questions was used. The focus group was conducted by a NYSDOH researcher (A.S.H.) and a second researcher (S.R.M.) recorded and transcribed the responses.

WIC focus group participants were subsequently invited to complete individual telephone interviews. These semistructured interviews were used to obtain more in-depth personalized feedback from focus group participants only. The phone interviews were administered from July 2014 to November 2014 by a NYSDOH researcher (A.S.H.). Interview participants were informed that their responses were strictly confidential and identifying information would not be further utilized. Participant responses were recorded and transcribed by a second researcher (S.R.M.).

Based on information received from the focus group and interviews, an anonymous online survey was developed and offered to all WIC staff members in the affected areas to identify their most important challenges and recommendations. All focus group and interview participants were also invited to participate. The Guidance Team collaborated with focus group participants to identify and reach additional WIC and VMA staff located in Nassau County, Suffolk County, Westchester County and NYC for participation. Only staff members who had been involved in Sandy preparedness, response and recovery activities between 26 October 2012 and 21 November 2012 were eligible to participate.

The survey was developed and administered in January 2015 using SurveyMonkey ${ }^{\odot}$. The WIC staff, identified in the affected areas, were emailed the survey link and given four weeks to complete the survey electronically; reminders were also sent by email. They were also offered the option to complete a paper version of the survey delivered by mail. Survey participants were given the option of skipping questions they did not wish to answer.

\section{Qualitative analysis}

Focus group and interview transcripts were evaluated for accuracy before being analysed and coded by two 
independent coders (A.S.H. and S.R.M.) using open coding and grounded theory methodology ${ }^{(13)}$ and NVivo version 10 software (QSR International, Melbourne, Australia). A codebook developed and used in an earlier Sandy study was used for coding ${ }^{(9)}$. Intercoder reliability was assessed using percentage agreement and Cohen's kappa. If a code with less than $80 \%$ agreement or with $\kappa$ lower than 0.7 was encountered, it was re-examined and negotiated until agreement was reached.

The coders identified key words that were subsequently classified as strengths, challenges or recommendations based on the context in which they were used. These key words were then categorized by eleven Public Health Preparedness Capabilities developed by the $\mathrm{CDC}^{(12)}$ and six other studydefined preparedness capability categories, including a miscellaneous category ${ }^{(9)}$ (Table 1). The study-defined preparedness capability categories were developed to accommodate key words that fit into multiple CDC preparedness capabilities. One open-ended survey question that inquired about recommendations for improving future preparedness, response and recovery was also coded and categorized in this manner. Identified key words were used to explore major and minor themes in the form of preparedness capabilities and their corresponding strengths, challenges and recommendations. For selected preparedness capability categories representing these themes, examples of strengths, challenges and recommendations along with participant quotations are presented.

\section{Quantitative analysis}

The anonymous online survey consisted of twenty-eight questions covering participant employment information, the impact of Sandy on the continuity of WIC services, challenges encountered during and in the aftermath of Sandy, preparedness for future disasters, and recommendations for improving preparedness, response and recovery efforts in the future. Responses were recorded using yes/no, multiplechoice, Likert-scale and open-ended questions. Frequency distributions and percentages of survey question responses were generated and analysed using the statistical software package SAS ${ }^{\text {TM }}$ versions 9.3 and 9.4. Due to small numbers and concerns about non-normal distribution of some data, Spearman's rank-order correlation and Kruskal-Wallis tests were performed using SAS. A summary challenge impact variable was created by summing the total number of times participants indicated that they had faced a challenge inquired about in a survey question.

\section{Results}

At the WIC Directors' Meeting, eleven WIC staff and one VMA participated in the focus group. Of these twelve

Table 1 Public health preparedness capabilities used to categorize key words from qualitative data in 2014 WIC provider focus group and interviews and 2015 surveys $^{(9)}$

\begin{tabular}{|c|c|}
\hline Preparedness capabilities & Definition \\
\hline \multicolumn{2}{|l|}{ CDC-defined capabilities ${ }^{(12)}$} \\
\hline Community preparedness & Ability of communities to prepare for, withstand and recover \\
\hline Community recovery & $\begin{array}{l}\text { Ability to collaborate with community partners to plan and advocate for the rebuilding of public } \\
\text { health systems }\end{array}$ \\
\hline Emergency operations coordination & $\begin{array}{l}\text { Ability to direct and support an event or incident with public health or medical implications } \\
\text { by establishing oversight, organization and supervision }\end{array}$ \\
\hline $\begin{array}{l}\text { Emergency public information } \\
\text { and warning }\end{array}$ & $\begin{array}{l}\text { Ability to develop, coordinate and disseminate information, alerts and notifications to the public } \\
\text { and incident management responders }\end{array}$ \\
\hline Information sharing & $\begin{array}{l}\text { Ability to conduct multijurisdictional exchange of health-related information and situational } \\
\text { awareness data }\end{array}$ \\
\hline Mass care & $\begin{array}{l}\text { Ability to coordinate with partner agencies to address public health, medical and mental/ } \\
\text { behavioural health needs of those impacted }\end{array}$ \\
\hline Medical countermeasure dispensing & Ability to provide medical countermeasures \\
\hline Medical material management & Ability to acquire, maintain, transport, distribute and track medical material during an incident \\
\hline Medical surge & $\begin{array}{l}\text { Ability to provide adequate medical evaluation and care during events that exceed the limits } \\
\text { of the normal medical infrastructure }\end{array}$ \\
\hline $\begin{array}{l}\text { Public health epidemiological } \\
\text { investigation and surveillance }\end{array}$ & $\begin{array}{l}\text { Ability to create, maintain, support and strengthen routine surveillance and detection systems } \\
\text { and epidemiological investigation processes }\end{array}$ \\
\hline Volunteer management & $\begin{array}{l}\text { Ability to coordinate the identification, recruitment, registration, credential verification, training } \\
\text { and engagement of volunteers to support the public health agency's response to incidents } \\
\text { of public health significance }\end{array}$ \\
\hline \multicolumn{2}{|l|}{ Other capabilities ${ }^{(9) *}$} \\
\hline Environmental health protection & Ability to protect the public from environmental hazards \\
\hline Flexibility & Ability to respond based on flexibility in funding, reimbursement, regulations and law \\
\hline Planning & $\begin{array}{l}\text { Plan, implement and modify current plans/policies/protocols or the ability to develop new plans/ } \\
\text { policies as needed to respond to the incident }\end{array}$ \\
\hline Roles and responsibilities & $\begin{array}{l}\text { Ability to respond efficiently due to leadership, roles and responsibilities being clearly } \\
\text { understood and adhered to }\end{array}$ \\
\hline Training and preparedness & Adequate training initiatives, drills and/or exercises developed prior to the disaster \\
\hline Miscellaneous & Remaining items that did not fit into a capability \\
\hline
\end{tabular}

WIC, Special Supplemental Nutrition Program for Women, Infants, and Children; CDC, Centers for Disease Control and Prevention.

${ }^{*}$ Capabilities defined for the present study's purposes. 
focus group participants invited to complete an individual interview, six (50.0\%) completed it. Five WIC programmes and one VMA were represented. Of fifty-three WIC staff members and one VMA staff member identified by the Guidance Team in the three affected counties and NYC who were invited by email to participate in the anonymous survey, including focus group and interview participants, twenty-five ( $46 \cdot 3 \%)$ responded to the survey. One survey participant was then excluded from the analysis because they had not assisted with preparedness, response and recovery activities related to Sandy. Participants in all three phases of the study combined represented WIC sites situated at LHD, hospitals, federally qualified health centres and other locations.

\section{Qualitative (focus group, interview and survey) results}

Key words were identified from the transcribed text of the focus group, interviews and one open-ended survey question. Key words were then categorized as strengths, challenges or recommendations and classified by preparedness capability. Major (the top three) and minor themes were identified (Table 2).

\section{Strengths}

Three major preparedness capability themes related to strengths of the WIC programme's preparedness and response were identified. These were 'emergency operations coordination', 'flexibility' and 'information sharing' preparedness capabilities. Within the 'emergency operations coordination' theme, the willingness and dedication exhibited by staff in providing services to their clients was a commonly cited strength. In the aftermath of Sandy, some staff took on extra coordination responsibilities to support accessibility of WIC services despite the negative impacts (loss of electricity at their homes, damage to or even loss of their homes, etc.) they had experienced themselves due to Sandy.

Under the 'flexibility' capability theme, the flexibility displayed by WIC sites in accepting clients transferred from other WIC sites was a strength. Such WIC sites provided services and assistance to clients unable to obtain service from their regular WIC site. For the information sharing' capability theme, a strength was maintenance of valuable internal communication. Specifically, internal communication between staff members situated at various health departments or WIC providers' offices was generally clear, well-planned and sustained throughout Sandy's aftermath.

The 'planning' and 'emergency public information and warning' preparedness capability themes were minor themes representing strengths in the WIC programme's emergency preparedness and response efforts. Ten other preparedness capabilities combined accounted for just $20.7 \%$ of all strength key words and thus were classified as minor themes. No strengths related to 'medical countermeasure dispensing' or 'medical material management' preparedness capabilities were reported.

\section{Challenges}

The challenge of 'environmental health protection' was a major theme. Flooding was a commonly encountered threat to environmental health. It resulted in damage to servers, electronic equipment, computers, paperwork, food stores and site buildings. Flooding also contributed to unsanitary conditions at many host sites due to mould and the intermixing of flood and sewer water. Due to such destruction, staff at some sites were unable to access lists of monthly active participants via the NYS WIC Statewide Information System (WICSIS), an administrative database for the NYS WIC programme. Flooding also severely limited both staff and client access to WIC provider sites due to destruction of the site and/or transportation barriers.

Difficulty in 'emergency operations coordination' was a second major challenge theme. Coordination challenges included problems in associating and validating manually written WIC food cheques (WIC cheques are usually generated by computer) due to a lack of resources for emergency operations. Resources lacked included computers, staff and even suitable locations at which to work. Some staff experienced difficulty reporting to work to coordinate their programme's response due to transportation issues and being personally affected by Sandy. Many WIC sites had suffered damage from Sandy, and many were without electricity, creating a need for temporary workspaces. WIC provider challenges related to 'flexibility' in programme operations was the third major challenge theme. WIC staff found manual cheques tedious to write and faced difficulty in associating and validating them. Provider sites often had no way to self-produce manual cheques and some did not have enough cheques in stock for use in the aftermath of Sandy. Further complicating the use of manual cheques, a number of stores were inflexible in their procedures for accepting WIC cheques, sometimes refusing to accept them.

The 'information sharing' and 'community recovery' preparedness capabilities were minor themes posing challenges to WIC programmes. As additional minor themes, nine other preparedness capabilities accounted for $17.8 \%$ of all challenge key words. No challenges related to 'volunteer management', 'medical countermeasure dispensing' or 'public health epidemiological investigation and surveillance' were identified.

\section{Recommendations}

There were numerous recommendations for improving the WIC programme's 'flexibility' in emergency events, a major recommendations theme. Recurring recommendations included the need for flexibility in obtaining backup computers and laptops, accessing an internet (rather than intranet)-based WICSIS, and establishing mobile centres and/or temporary WIC sites for emergency use. 
Table 2 Quotations by preparedness capability themes: 2014 WIC provider focus group and interviews and 2015 survey

\begin{tabular}{|c|c|c|}
\hline Preparedness capability themes & Selected key words & Quotes \\
\hline \multicolumn{3}{|l|}{ Major strength themes } \\
\hline Emergency operations coordination & Staff response & $\begin{array}{l}\text { 'The best thing is when you work with people and you don't know them until something happens .. } \\
\text { [The staff] would still come in and spend seven hours sitting and talking and calling and go hom } \\
\text { before the sun goes down because they had to clean. It was phenomenal.' }\end{array}$ \\
\hline Flexibility & WIC transfers & $\begin{array}{l}\text { 'We did tell other WIC programmes that we were here if they needed to transfer their clients to us } \\
\text { temporarily.' }\end{array}$ \\
\hline Information sharing & Communication & $\begin{array}{l}\text { 'Core of everything we do is communication and I feel like here in the [agency] we did a good job } \\
\text { planning in advance and communicating. We had regular phone calls. About what to expect, wha } \\
\text { were the plans.' }\end{array}$ \\
\hline \multicolumn{3}{|l|}{ Example minor strength themes } \\
\hline Planning & Planning & $\begin{array}{l}\text { 'Basically, my boss was contacted by her superiors in the } \mathrm{DOH} \text { to call every employee to start } \\
\text { mobilizing and start a plan to take care of our participants. We were mobilized the day before.' }\end{array}$ \\
\hline $\begin{array}{l}\text { Emergency public information and } \\
\text { warning }\end{array}$ & Public communication & $\begin{array}{l}\text { 'One site we did evacuate people home, but we closed the clinic at that time and were able to leave } \\
\text { messaging for clients that it was closed and about the two other sites. Had someone that lived in } \\
\text { that community go to the office and put signage on the door in case anyone showed up.' }\end{array}$ \\
\hline \multicolumn{3}{|r|}{ 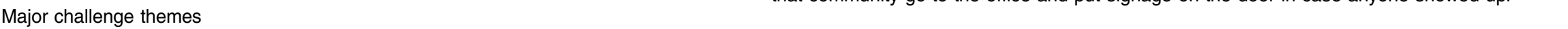 } \\
\hline Environmental health protection & Flooding & $\begin{array}{l}\text { 'The combination of bay water, sewer water, ocean water ... We didn't want to set foot in our offices } \\
\text { Even all our prep plans and all our policy papers and everything were gone.' }\end{array}$ \\
\hline Emergency operations coordination & Resource management & $\begin{array}{l}\text { 'Driving back and forth picking up equipment to get the place up and running. Staff members. Told to } \\
\text { make this a temp site. Try to get computers. Had to wait for computers from the site. That took } \\
\text { time.' }\end{array}$ \\
\hline Flexibility & WIC resources & $\begin{array}{l}\text { 'NYS vendors have to fill in entirety or can't take the WIC cheque. So some vendors might have milk } \\
\text { some might have different types of WIC-acceptable items, but even though they had some stuff } \\
\text { they couldn't take the cheque because they have to fill it in its entirety.' }\end{array}$ \\
\hline \multicolumn{3}{|r|}{ 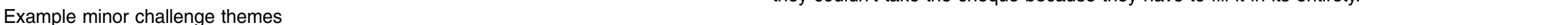 } \\
\hline Information sharing & Data accessibility & $\begin{array}{l}\text { 'Major problem with WICSIS computer system ... If it was internet-based system, we could have } \\
\text { worked from our cars or a rented van with a laptop.' }\end{array}$ \\
\hline Community recovery & Facilities & $\begin{array}{l}\text { 'Office totally gone. Under } 5 \text { feet of water. Putting things up on tables was not effective. All the tables } \\
\text { were moved. Things were blown into different locations ... Even temp equip was damaged. So } \\
\text { couldn't even use temp site.' }\end{array}$ \\
\hline \multicolumn{3}{|l|}{ Major recommendation themes } \\
\hline Flexibility & WIC resources & $\begin{array}{l}\text { 'They already have temporary WIC stations on a dolly in upstate NY. They roll it in. I don't understanc } \\
\text { why we can't have that ... They open up in the fire station. They have people come in for } \\
\text { appointments, they print their cheques, and then they pack up.' }\end{array}$ \\
\hline Information sharing & Partner communication & $\begin{array}{l}\text { 'Basically prior to storm I think that every agency should be emailed with what is expected of us. } \\
\text { There should be better contact with regional office.' }\end{array}$ \\
\hline Emergency operations coordination & Resource management & $\begin{array}{l}\text { 'Access to another WIC office. To resources from other WIC agencies if they have extra. They have } \\
\text { spare computer, they could give us one.' }\end{array}$ \\
\hline \multicolumn{3}{|l|}{ Example minor recommendation themes } \\
\hline Planning & Protocol & $\begin{array}{l}\text { 'They should email us something to put things higher up on a higher level. There has to be a } \\
\text { directive.' }\end{array}$ \\
\hline Public information and warning & Public communication & $\begin{array}{l}\text { 'Basically, what we suggest is that they have radio announcements with updates. The county has } \\
\text { announcements saying this clinic is closed this clinic is open. You need to go here. Please call this } \\
\text { number.' }\end{array}$ \\
\hline
\end{tabular}

WIC, Special Supplemental Nutrition Program for Women, Infants, and Children; DOH, Department of Health; NYS, New York State; WICSIS, WIC Statewide Information System. 
There were also many recommendations belonging to another major theme 'information sharing', including improved partner communication. WIC provider sites expressed a desire for better communication of expectations and greater support from partner agencies such as regional health offices and the state health department. WIC staff reported the need for more frequent communication with state and regional health departments prior to and in the aftermath of Sandy regarding disaster planning and preparation, WIC providers' needs and actions to take. Some staff recommended that state and regional health offices establish contact with WIC provider sites more immediately after Sandy and that information should be conveyed to WIC sites faster. The importance of holding a debriefing session for WIC providers led by the state health department soon after Sandy was also emphasized. Some staff noted that communication with WIC vendors might be improved by establishing alternative methods of communication in addition to by telephone.

Recommendations under the 'emergency operations coordination' capability major theme included suggestions for increased coordination and sharing of basic resources, such as cheque stock paper and toner, between WIC offices during emergencies.

For minor themes, other recommendations belonged to the 'planning' and 'training and preparedness' preparedness capabilities. Six other preparedness capabilities accounted for $15.8 \%$ of all recommendation key words when combined. There were no recommendations for improving 'environmental health protection', 'mass care', 'medical surge', 'medical countermeasure dispensing', 'public health epidemiological investigation and surveillance' or 'volunteer management' reported.

\section{Quantitative (survey) results}

Out of the twenty-four survey participants, the primary functional job titles reported were 'WIC Director/Coordinator/Site manager' (38.9\%, $n$ 7), 'Nutritionist/CPA' $(33.3 \%, n 6)$ and 'Clerical support' $(27.8 \%, n 5)$. CPA is the abbreviation for competent professional authority. Six participants did not report a job title.

The median number of years participants had been employed by or contracting for a WIC programme was 7 (range $2-30 ; n$ 18). The median number of years participants had been employed or contracted to work in a public health field was 15 (range $2-31 ; n$ 17). During the Sandy survey period, sixteen (94.1\%) participants were full-time employees with WIC and one (5.9\%) was a parttime employee with WIC (seven did not report their employee status). Twelve (66.7\%) participants reported that their WIC programme was part of an LHD while six $(33.3 \%)$ reported their WIC programme was not (six did not provide a response). Nine ( $45.0 \%)$ staff described the overall impact of Sandy on their WIC programme as severe, eight $(40.0 \%)$ staff described the impact as moderate, and one (5.0\%) staff member was unsure of the impact (four staff did not respond with an impact level).

\section{Challenges}

Challenges reported on the survey were categorized by preparedness capability (Fig. 1). The most commonly reported challenges were in the 'information sharing' preparedness capability. Within this capability, all of those responding to the questions indicated difficulty contacting WIC recipients ( $n$ 18), the general public ( $n$ 19) and their colleagues at other government agencies ( $n$ 16), although some did not answer these questions. Most also reported problems corresponding with staff in their own programme $(94.7 \%, n 18 / 19)$, disruptions in phone service $(93 \cdot 8 \%, n$ 15/16) and barriers to accessing NYS WICSIS $(81 \cdot 3 \%, n 13 / 16)$. WIC staff reported that information was most often shared with WIC recipients by phone $(77.8 \%$, $n 14 / 18)$, in person $(61 \cdot 1 \%, n 11 / 18)$ and postal service $(27 \cdot 8 \%, n 5 / 18)$. Text messaging (11.1\%, $n 2 / 18)$ and fax $(5.6 \%, n 1 / 18)$ were rarely used, and other modes of communication such as email, website and social media were never used. One participant $(5.6 \%, n 1 / 18)$ reported being unsure of how information was communicated to WIC recipients.

WIC providers encountered many challenges in 'emergency operations coordination' (Fig. 1). All respondents $(n 17)$ indicated that routine WIC service operations were interrupted by Sandy. Providers also experienced transportation-related challenges, including problems obtaining fuel $(100 \cdot 0 \%, n 15 / 15)$ and trouble procuring vehicles $(58.8 \%, n 10 / 17)$. Most staff reported the absence of generators $(75.0 \%, n$ 12/16). While Sandy's impact prevented some WIC staff from reporting to work ( $44 \cdot 4 \%$, $n$ 8/18), there were few problems with staff being unwilling to volunteer $(6 \cdot 3 \%, n 1 / 16)$ and no reports $(0 \cdot 0 \%, n$ 0/17) of staff being unwilling to perform duties outside their normal scope.

The final three preparedness capabilities reported as challenges in the survey included 'environmental health protection', 'community recovery' and 'flexibility' (Fig. 1). The majority of participants dealt with power outages $(94.4 \%, n 17 / 18)$ and limited access to worksites $(77.8 \%$, $n$ 14/18), challenges classified under 'environmental health protection' and 'community recovery' preparedness capabilities, respectively. Within the 'flexibility' category, $70 \cdot 6 \%(n$ 12/17) of participants reported challenges accessing storm-restricted areas, 56.3\% ( $n$ 9/16) reported challenges in accepting WIC client transfers from other provider sites and $41.2 \%(n 7 / 17)$ reported challenges in transferring WIC clients to other provider sites.

\section{Preparedness for Superstorm Sandy}

Figure 2 summarizes WIC staff members' average agreement with several preparedness-related statements in respect to their experiences during Sandy. Using a five- 


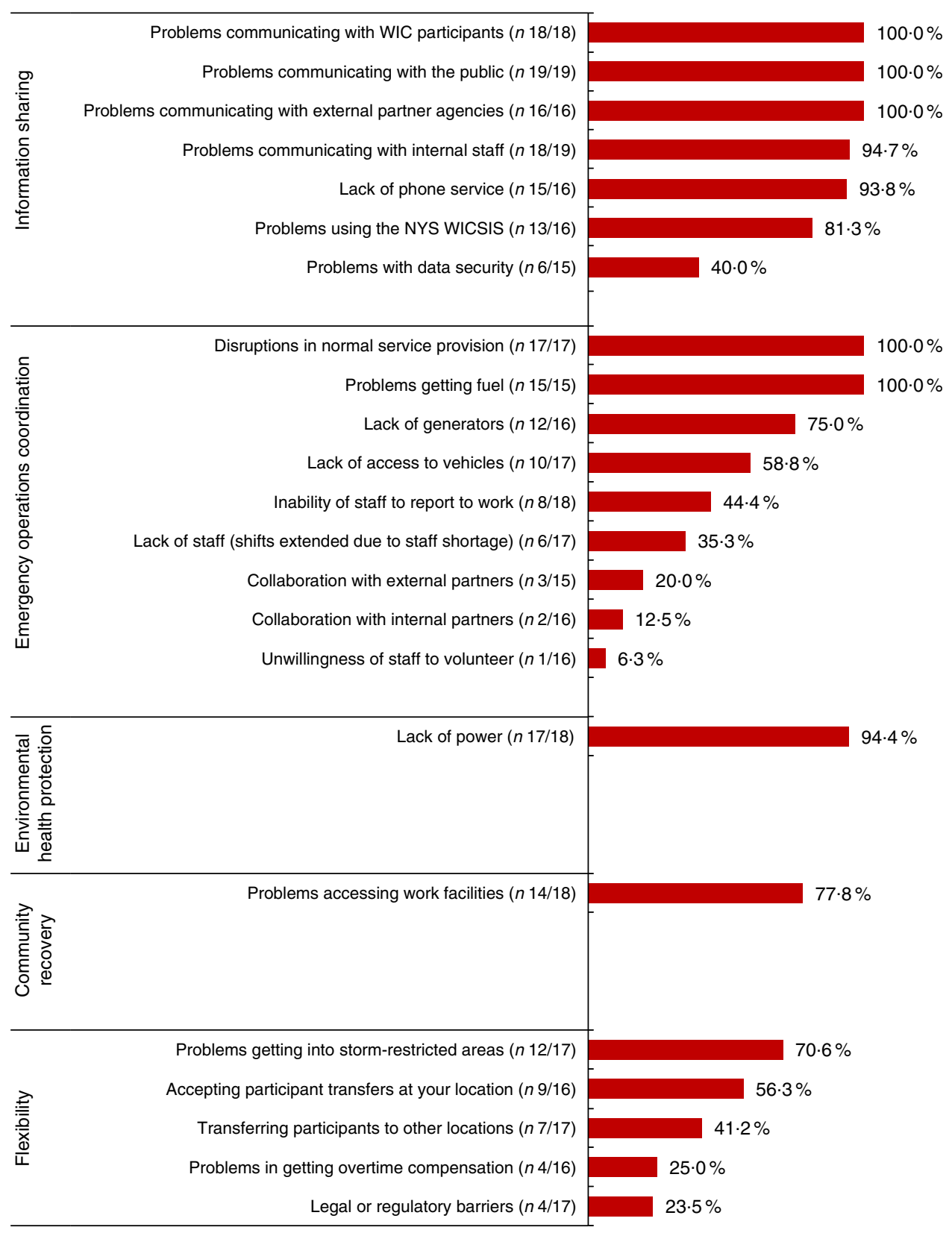

Fig. 1 (colour online) Challenges by preparedness capability: results from the 2015 WIC provider survey evaluating Superstorm Sandy's impact on provision of WIC services in NYS during the Sandy survey period of 26 October 2012 to 21 November 2012 (WIC, Special Supplemental Nutrition Program for Women, Infants, and Children; NYS, New York State; WICSIS, WIC Statewide Information System)

point Likert scale (with 1 representing 'strongly disagree' and 5 representing 'strongly agree'), most WIC staff agreed that their responsibilities were clearly defined to them (mean $4 \cdot 0, n$ 18), that existing resources were adequate to sustain WIC services (mean $3 \cdot 8, n$ 18) and that they had access to information necessary to perform their job duties (mean $3 \cdot 7, n$ 18).

Staff expressed the lowest level of agreement with the statement that their emergency training was sufficient preparation (mean $3 \cdot 4, n$ 17), and one respondent was unsure. Those reporting fewer challenges in the survey had significantly $(P<0.05)$ greater agreement that staff members' responsibilities were clearly defined to them (Spearman's rank-correlation coefficient $\left(r_{s}\right)=0.579$ ), that staff had access to information necessary to perform their job duties $\left(r_{s}=0.544\right)$ and that emergency training was sufficient preparation $\left(r_{s}=0.665\right)$.

\section{Preparedness for future disasters}

Figure 3 summarizes WIC staff members' perception of their personal level of preparedness for future weatherrelated disasters as well as their WIC programme's level of preparedness. More than two-thirds $(70 \cdot 6 \%, n$ 12/17) of WIC providers reported that they, as an employee, were 


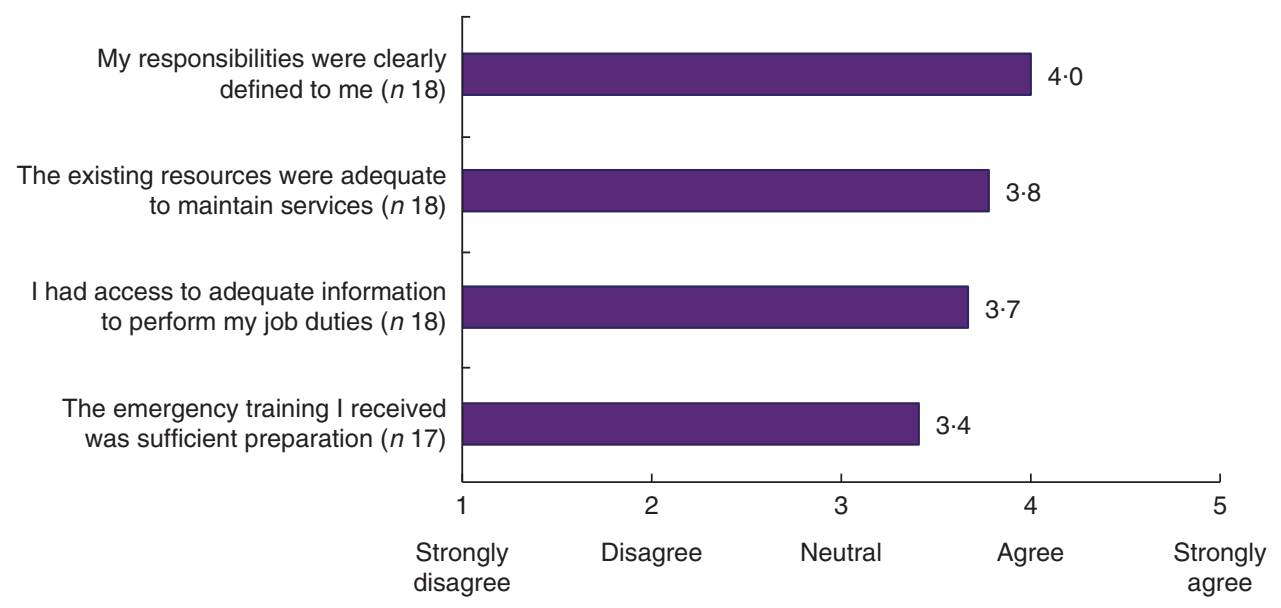

Fig. 2 (colour online) WIC staff members' mean agreement with various preparedness-related statements in respect to their experiences in provision of WIC services in NYS during during the Superstorm Sandy survey period of 26 October 2012 to 21 November 2012: results from the 2015 WIC provider survey (WIC, Special Supplemental Nutrition Program for Women, Infants, and Children; NYS, New York State)

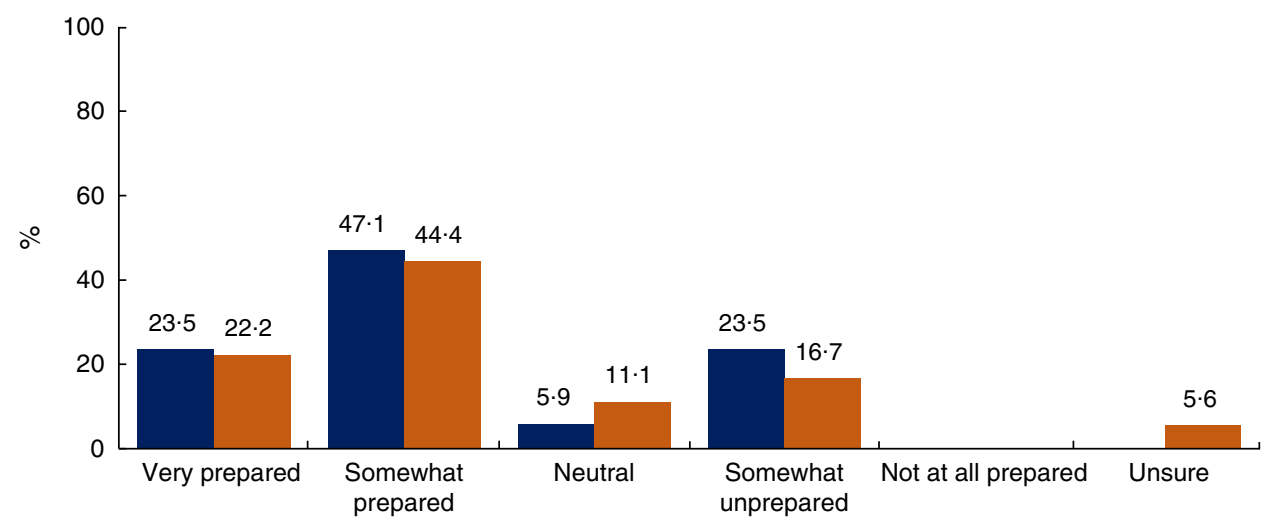

Fig. 3 (colour online) Perception of preparedness for future weather-related disasters ( $\square$, as an employee, $n 17$; $\square$, WIC programme, $n$ 18): results from the 2015 WIC provider survey evaluating Superstorm Sandy's impact on provision of WIC services in NYS during the Sandy survey period of 26 October 2012 to 21 November 2012 in 2012 (WIC, Special Supplemental Nutrition Program for Women, Infants, and Children; NYS, New York State)

somewhat or very prepared for future weather-related disasters. A slightly lower proportion $(66.6 \%, n 12 / 18)$ felt their WIC programme was somewhat or very prepared. No staff members rated themselves or their WIC programmes as 'not at all prepared', and only 5.6\% were unsure about their programmes.

When staff were asked if they had participated in practicing an emergency response plan at their WIC site since Sandy, only $16.7 \%(n 3 / 18)$ reported that they had. Employees who reported practicing an emergency response plan at their site were more likely to indicate that they, as an employee, were prepared for future weather-related disasters $(P<0.05)$. Only $27.8 \%(n 5 / 18)$ of staff reported that their WIC programme hosted annual weather-related emergency preparedness training for staff. However, more than half of the staff reported that their WIC programme had an emergency operations plan in place $(61 \cdot 1 \%, n 11 / 18)$, including protocols to advise clients of potential disruptions in WIC service prior to weather-related emergencies $(50 \cdot 0 \%, n 9 / 18)$.

\section{Discussion}

The present qualitative and quantitative assessment of the impact of Sandy on the WIC programme identified many potential areas for improvement. One area was emergency planning. WIC staff experienced difficulty sustaining the provision of services due to flood damage and inaccessible worksites. This limited access to electronic WIC client data and resulted in the disruption of communication (both within the programme and with clients) and routine services. The institution of plans for backing up data, securing mobile electronic equipment, establishing alternative worksites, maintaining communication with clients and colleagues, and educating staff about their duties during emergency situations would enhance the resiliency of WIC.

Communication problems were common. Communication between WIC staff, WIC recipients and other agencies could be improved by increased use of texting and social media platforms and the collection of alternative contact information from recipients. Other areas for improvement 
included clarifying flexibilities in WIC policies during disasters and coordinating the sharing of resources among WIC agencies. Interestingly, while client transfers between WIC sites was noted as a strength under the 'flexibility' capability for focus groups and interviews, both accepting and transferring WIC recipients was reported as a challenge by some survey respondents (Fig. 1). A possible explanation for this is that while WIC sites demonstrated flexibility in their emergency response through their ability to transfer WIC recipients or accept transfers, the transfer process itself was found to be inefficient or burdensome by some WIC staff. Finally, WIC staff should practice emergency training with a focus on preparedness and response activities unique to WIC programmes. The development of such training programmes by local WIC agencies in partnership with NYSDOH would be especially valuable because it would foster interagency communication critical to emergency response efforts and provide an opportunity to collect input from a variety of public health professionals. Following development of a training programme, it would be beneficial if all collaborators determined a schedule for the routine review of the programme.

No published assessments were identified for the effects of natural disasters on WIC programmes. However, several studies have examined the impact of Sandy on NYSDOH and $\mathrm{LHD}^{(9-11)}$, with similar results to the current assessment. In those studies, the public health agency preparedness capabilities 'emergency operations coordination' and 'information sharing' contained the greatest number of strengths, and challenges were commonly related to 'emergency operations coordination' and 'environmental health protection' ${ }^{(9,10)}$. Survey responses indicated that while NYSDOH and LHD staff were generally prepared for Sandy, they faced a number of challenges including communication problems, operational issues, public health service interruptions and staffing challenges ${ }^{(11)}$.

Although challenge key words comprised most of the key words identified, a number of notable strengths were also identified. The commitment of WIC staff to meeting the needs of their constituents was frequently acknowledged. This same commitment has been highlighted in studies of the response of public health workers in tuberculosis control programmes to Hurricane Katrina ${ }^{(14)}$ and Sandy ${ }^{(3)}$. WIC staff were willing to take on additional responsibilities such as working in special needs shelters, accommodating WIC recipients outside their service areas, and making efforts to maintain contact with their colleagues and WIC recipients.

Sandy caused substantial damage to WIC programme resources essential for the provision of services. It also made important locations, e.g. worksites, inaccessible. Flooding was a major issue, destroying paperwork, WIC identification cards, servers, computers and other electronic equipment. The loss of WIC identification cards may be less of an issue in the future as NYSDOH plans to pilot the use of WIC plastic benefits cards in 2018. Sandy resulted in some sites losing power and left others inaccessible to both WIC providers and their clients. During Hurricane Katrina, the Louisiana Tuberculosis Control Program faced similar concerns. The programme's main building housing the state's tuberculosis testing laboratory and stockpiles of medication was flooded, making it unreachable ${ }^{(14)}$. Other public health programmes were also impacted by the uninhabitable conditions created by Hurricane Katrina, including the HIV Outpatient Program $(\mathrm{HOP})^{(15)}$. HOP clinics were constructed in new temporary sites to enable the provision of services.

Lessons learned from other public health programmes can be helpful in improving WIC preparedness. A CDC study found improvements in continuity of care received by patients suffering from tuberculosis in Sandy-affected areas compared with patients in Katrina-affected areas ${ }^{(3)}$. These improvements likely resulted from preparedness activities including the creation of line lists with names of patients likely to be impacted, the provision of treatment to patients for self-administration, relocating medications to secure places, making backup copies of patient records, providing patients with a list of health department contacts and phone numbers, and collecting contact information for patients' friends and family living in unaffected areas. Continuity of care can be improved based on analysis of problems in previous storms such as Hurricane Katrina in $2005^{(14,16)}$. Following Hurricane Katrina, HOP recommendations called for the backup of electronic clinical records ${ }^{(15)}$.

Data inaccessibility was a persistent problem for WIC providers. Many data accessibility issues for the WIC programme resulting from Sandy were due to providers' inability to access WICSIS (an intranet-based system) as a result of damage to servers. Resources including computers, fuel, generators, access to vehicles and even staff to sustain the programme were limited during Sandy. WIC programmes must ensure that they have the resources necessary to support the provision of some level of services during disasters. This entails protecting current resources and securing backup ones. It is essential to store electronic equipment and important resources in protected locations, back up data to a secure source and pre-identify temporary WIC sites.

Information sharing also represented a gap in the WIC programmes' preparedness and response. Programmes should establish information-sharing networks to communicate with both colleagues and WIC recipients during emergencies. This might involve compiling and regularly updating emergency contact lists or exploring other means of communication through cell phones, social media or email. Tuberculosis control programmes in regions affected by natural disasters such as Hurricane Katrina ${ }^{(14)}$, Hurricanes Gustav and Ike ${ }^{(16)}$ and Sandy ${ }^{(3)}$ have made good use of information sharing as a tool to ensure continuity of service. During Hurricane Katrina, public 
health agencies established a Katrina TB Helpdesk to reconnect displaced tuberculosis patients with care ${ }^{(14)}$.

Emergency response training and planning would equip WIC staff with the ability to work efficiently during emergencies. The present study indicated that not all WIC programmes regularly practice WIC-specific emergency response plans despite potentially having them in place. In the future, training conducted should include relevant staff members and emphasize preparedness activities of particular importance to WIC staff, such as collecting alternative contact information from clients, clarifying WIC policies with vendors, and printing copies of monthly active participants on a monthly basis. NYSDOH and WIC agencies should determine how often existing policies and materials regarding emergency training should be reviewed. NYSDOH might consider contributing to the development and delivery of updated training. Collaboration between NYSODH and WIC providers would be helpful in identifying the format in which training should be delivered, deciding how often emergency response plans should be practiced and determining the appropriate level of training for different staff members.

In future emergency situations, there are several steps WIC providers could take to support continuity of services. Data should be securely stored on multiple devices, including external drives such as USB devices or even a device at an off-site location. It is also helpful to identify alternative workspaces in case the current workspace becomes inaccessible or unusable during an emergency event. Clients can be notified of these alternative locations in advance of an emergency event. The collection of primary and alternative contact information by WIC agencies from both clients and vendors would facilitate clients' access to WIC services during emergencies. Educating vendors on the application of WIC policies during emergency events would be beneficial. Finally, training and preparedness plans developed might emphasize ways to enhance interagency communication and resource sharing.

The data for the present study had limitations. The limited number of impacted WIC providers in the three counties and NYC resulted in small numbers of staff members participating in the focus group, interviews and survey. This restricted our ability to assess subgroup differences. Additionally, generalizability is uncertain because participants were volunteers rather than randomly selected.

Participation rates were similar for both the interviews (50.0\%) and survey (46.3\%). Non-participants may have felt they had fully shared their experiences through the focus group. No information was available to compare participants with non-participants.

\section{Conclusion}

The impact of natural disasters on WIC programmes has not been previously addressed. The present study provides information integral to enhancing the resiliency of WIC programmes against a variety of emergencies, including both natural and man-made disasters. For the nearly 7.7 million women, infants or children receiving WIC services nationwide each month in fiscal year $2016^{(17)}$, disruption of the programme could have serious health consequences.

Some of the present study's results are directly relevant to improving the emergency preparation and response of other public health services. Furthermore, the study's mixed-methods methodology can be applied to assessments of the impact of emergency events on other public health programmes. While many of the emergency preparedness recommendations for WIC providers generated by the study were general and not unexpected, the feedback suggests room for improvement in WIC programmes' emergency preparedness and response.

The maintenance of WIC services is critical to ensuring the well-being of particularly vulnerable populations. The findings of the present study indicate the need to incorporate public health programmes such as WIC into emergency response plans, in addition to encouraging them to develop their own. As climate change remains a growing threat to the USA and weather-related disasters become increasingly common ${ }^{(18)}$, we must ensure that we can continue to provide for our most vulnerable citizens.

\section{Acknowledgements}

Acknowledgements: The authors thank Dr Tavora Buchman, Nassau County Department of Health, Co-Principal Investigator; Mr Michael Primeau and the Office of Health Emergency Preparedness, NYSDOH; and members of the Research Guidance Team for their input into the study design. Financial support: This work was supported by the CDC (Cooperative Agreement Number U01TP000567). The CDC had no role in the design, analysis or writing of this article. The contents of this publication are solely the responsibility of the authors and do not necessarily represent the official views of the CDC or the NYSDOH. Conflict of interest: None. Authorship: M.W. conducted data analysis and wrote the manuscript. A.S.H., as the study's Project Coordinator, organized the survey components, including distribution and collection, and the information presented in this manuscript. S.R.M. provided analysis of survey data and developed the figures included in this manuscript. Y.L. provided analysis of the survey data. M.E., as a study Co-Principal Investigator, provided oversight for the development of this study and this manuscript. L.A.S. served on the Guidance Team and edited this manuscript. T.N., as a study Co-Principal Investigator, provided oversight for the development of this study, analysis of survey data, development of the figures and edits to this manuscript. G.S.B., as the study Principal Investigator, provided oversight for the development of this study and edits to this manuscript. Ethics of buman subject participation: Approval for the collection and use of the data was received from the NYSDOH Institutional 
Review Board. This study was conducted according to the guidelines laid down in the Declaration of Helsinki and all procedures involving human subjects were approved by the NYSDOH Institutional Review Board. Written and verbal informed consent was obtained from all study participants. Verbal consent was witnessed and formally recorded.

\section{References}

1. Blake ES, Kimberlain TB, Berg RJ et al. (2013) Tropical Cyclone Report Hurricane Sandy (AL182012), 22-29 October 2012. http://www.nhc.noaa.gov/data/tcr/AL182012_Sandy. pdf (accessed March 2016).

2. Powell T, Hanfling D \& Gostin LO (2012) Emergency preparedness and public health: the lessons of Hurricane Sandy. JAMA 308, 2569-2570.

3. Centers for Disease Control and Prevention (2013) Tuberculosis control activities before and after Hurricane Sandy - Northeast and Mid-Atlantic States, 2012. MMWR Morb Mortal Wkly Rep 62, 206-208.

4. Pouget ER, Sandoval M, Nikolopoulos GK et al. (2015) Immediate impact of Hurricane Sandy on people who inject drugs in New York City. Subst Use Misuse 50, 878-884.

5. Callaghan WM, Rasmussen SA, Jamieson DJ et al. (2007) Health concerns of women and infants in times of natural disasters: lessons learned from Hurricane Katrina. Matern Child Health J 11, 307-311.

6. Zotti ME, Williams AM \& Wako E (2015) Post-disaster health indicators for pregnant and postpartum women and infants. Matern Child Health J 19, 1179-1188.

7. Xiong X, Harville EW, Mattison DR et al. (2008) Exposure to Hurricane Katrina, post-traumatic stress disorder and birth outcomes. Am J Med Sci 336, 111-115.

8. Xiong X, Harville EW, Mattison DR et al. (2010) Hurricane Katrina experience and the risk of post-traumatic stress disorder and depression among pregnant women. Am J Disaster Med 5, 181-187.
9. Shipp Hilts A, Mack S, Eidson M et al. (2016) New York State public health system response to Hurricane Sandy: an analysis of emergency reports. Disaster Med Public Health Prep 10, 308-313.

10. Shipp Hilts A, Mack S, Eidson M et al. (2016) New York State public health system response to Hurricane Sandy: lessons from the field. Disaster Med Public Health Prep 10, 443-453.

11. Shipp Hilts A, Mack S, Li Y et al. (2016) New York State public health system response to Hurricane Sandy: an analysis of survey feedback. Disaster Med Public Health Prep 10, 454-462.

12. Centers for Disease Control and Prevention, Office of Public Health Preparedness and Response (2011) Public Health Preparedness Capabilities: National Standards for State and Local Planning. http://www.cdc.gov/phpr/capabilities/ dslr_capabilities_july.pdf (accessed March 2016).

13. Corbin J \& Strauss A (1990) Grounded theory research: procedures, canons, and evaluative criteria. Qual Sociol 13, 3-21.

14. Centers for Disease Control and Prevention (2006) Tuberculosis control activities after Hurricane Katrina - New Orleans, Louisiana, 2006. MMWR Morb Mortal Wkly Rep 55, 332-335.

15. Clark RA, Besch L, Murphy M et al. (2006) Six months later: the effects of Hurricane Katrina on health care for persons living with HIV/AIDS in New Orleans. AIDS Care 18, Suppl. 1, S59-S61.

16. Miner MC, Burns-Grant G, DeGraw C et al. (2010) Integrated preparedness for continuity of tuberculosis care after Hurricanes Gustav and Ike: Louisiana and Texas, 2008. Public Health Rep 125, 518-519.

17. Food and Nutrition Service, US Department of Agriculture (2017) Program Data - WIC Program. http://www.fns-prod. azureedge.net/sites/default/files/pd/wisummary.pdf (accessed September 2017)

18. Balbus J, Crimmins A, Gamble JL et al. (2016) The Impacts of Climate Change on Human Health in the United States: A Scientific Assessment. Washington, DC: US Global Change Research Program; available at http://www.dx.doi.org/ 10.7930/J0R49NQX 